\title{
The Identification and Analysis of Gas-Related Volcanic Features within Chang'e-5 Landing Region
}

\author{
Yuan Chen ${ }^{1,2, *}$, Xing Wang ${ }^{1,2} \mathbb{D}^{\text {, Jianjun Liu }}{ }^{1,2}$, Xin Ren ${ }^{1,2}$, Hai Huang ${ }^{1,2}$, Hongbo Zhang ${ }^{1,2}$ and Chunlai Li $^{1,2} \mathbb{C}$ \\ 1 Key Laboratory of Lunar and Deep Space Exploration, National Astronomical Observatories, \\ Chinese Academy of Sciences, Beijing 100101, China; wangx01@nao.cas.cn (X.W.); liujj@nao.cas.cn (J.L.); \\ renx@nao.cas.cn (X.R.); huangh@nao.cas.cn (H.H.); zhanghb@nao.cas.cn (H.Z.); licl@nao.cas.cn (C.L.) \\ 2 School of Astronomy and Space Science, University of Chinese Academy of Sciences, Beijing 100049, China \\ * Correspondence: cheny@nao.cas.cn
}

Citation: Chen, Y.; Wang, X.; Liu, J.; Ren, X.; Huang, H.; Zhang, H.; Li, C. The Identification and Analysis of Gas-Related Volcanic Features within Chang'e-5 Landing Region. Remote Sens. 2021, 13, 3879. https://doi.org/ $10.3390 /$ rs13193879

Academic Editors: Shengbo Chen, Lin Li and Yuanzhi Zhang

Received: 20 August 2021

Accepted: 23 September 2021

Published: 28 September 2021

Publisher's Note: MDPI stays neutral with regard to jurisdictional claims in published maps and institutional affiliations.

Copyright: (c) 2021 by the authors. Licensee MDPI, Basel, Switzerland. This article is an open access article distributed under the terms and conditions of the Creative Commons Attribution (CC BY) license (https:/ / creativecommons.org/licenses/by/ $4.0 /)$.

\begin{abstract}
Chang'e-5 (CE-5) successfully landed on the young basalts area in the northeastern Oceanus Procellarum on 1 December 2020. Recent studies on the CE-5 landing area have shown that the lack of gas-related volcanic morphology indicates that the volatile elements captured in the interior of the Moon within late-stage magma is relatively low. Typical lunar gas-related volcanic features include dark mantle deposits, volcanic pits, irregular mare patches and so on. Based on orbital images, topography, and spectral data obtained from multiple missions restricted by the morphologic and compositional characteristics of typical volcanic explosive features, this study investigated the morphological characteristics of the volcanic features in detail and found that there are three dark mantle deposits (DMDs) near the source area of Rima Mairan that have unusually low albedo and abnormally high titanium and iron content than those of the surrounding material. Combined with $\mathrm{M}^{3}$ spectral analysis, it is shown that DMDs contain some volcanic glass components, which indicates a gas-rich explosive eruption process. In addition to DMDs, irregular mare patches (IMPs) and a volcanic depression/pit have been recognized in this area, both of which indicate a history of gas-related volcanic eruptions. Based on this study and combined with past studies, we determined the volcanic history in the source area of Rima Mairan, including both effusive and explosive volcanic activities.
\end{abstract}

Keywords: Chang'e-5; Rima Mairan; dark mantle deposits; irregular mare patches; volcanic glass; volcanism and thermal evolution

\section{Introduction}

Chang'e-5 (CE-5) landed in the dark basalts area of Northeastern Oceanus Procellarum at 23:11 (UTC) on 1 December, 2020 and successfully returned with lunar samples on 17 December. The CE-5 landing area is located at the junction of Oceanus Procellarum and Sinus Roris, with highlands in the east, Imbrian basalts in the west, and Mons Rümker at $\sim 130 \mathrm{~km}$ in the southwest (Figure 1). The absolute model age (AMA) of the P58/Em4 unit where the CE-5 landing zone located is $~ 1.3-2.2 \mathrm{Ga}$, which belongs to the Eratosthenian and makes the CE-5 landing area as one of the youngest mare basaltic units on the Moon [1-4]. The morphology near the CE5 landing area has been extensively investigated. In addition to the non-mare domes and the mare domes within Mons Rümker, the other volcanic features include extensive mare basalts, Rima Sharp, Rima Mairan, and multiple possible volcanic vents $[3,5,6]$. The lack of gas-related volcanic morphology indicates that the amount of volatile elements captured in the interior of the Moon in magma is relatively low in the area where CE-5 is located [5].

Volatile elements provide insight into planet formation models and play a fundamental role in planetary evolution through their influence on melting, viscosity, and magma crystallization [7]. Traditional views believed that the Moon was poor in terms of volatile components. However, laboratory analyses on the composition of lunar samples have 
shown that lunar volcanic glass and some melt inclusion contains a small amount of volatile components [7,8]. A widespread occurrence of indigenous magmatic volatiles in pyroclastic materials sourced from deep lunar interiors have been identified using remote sensing observations [9]. Although the volatile content in the primitive magma is low, basaltic eruptions were always accompanied by different degrees of explosive processes due to the low gravity and vacuum environment of the Moon. These volatile components are mostly composed of the carbon monoxide (CO) generated at a depth of $\sim 50-300 \mathrm{~km}$ in dikes as well as the water vapor and sulfides that dissolved within a few hundred meters of the top of the dikes $[10,11]$. According to the volatile content of the magma, volcanic eruptions on the moon can be divided into different stages, corresponding to the formation of various volcanic morphologies [12]. Among them, gas-related typical volcanic features include dark mantle deposits (DMDs), pyroclastic cones and irregular mare patches (IMPs), ring-moat dome structure (RMDS), volcanic pits, etc. [12].

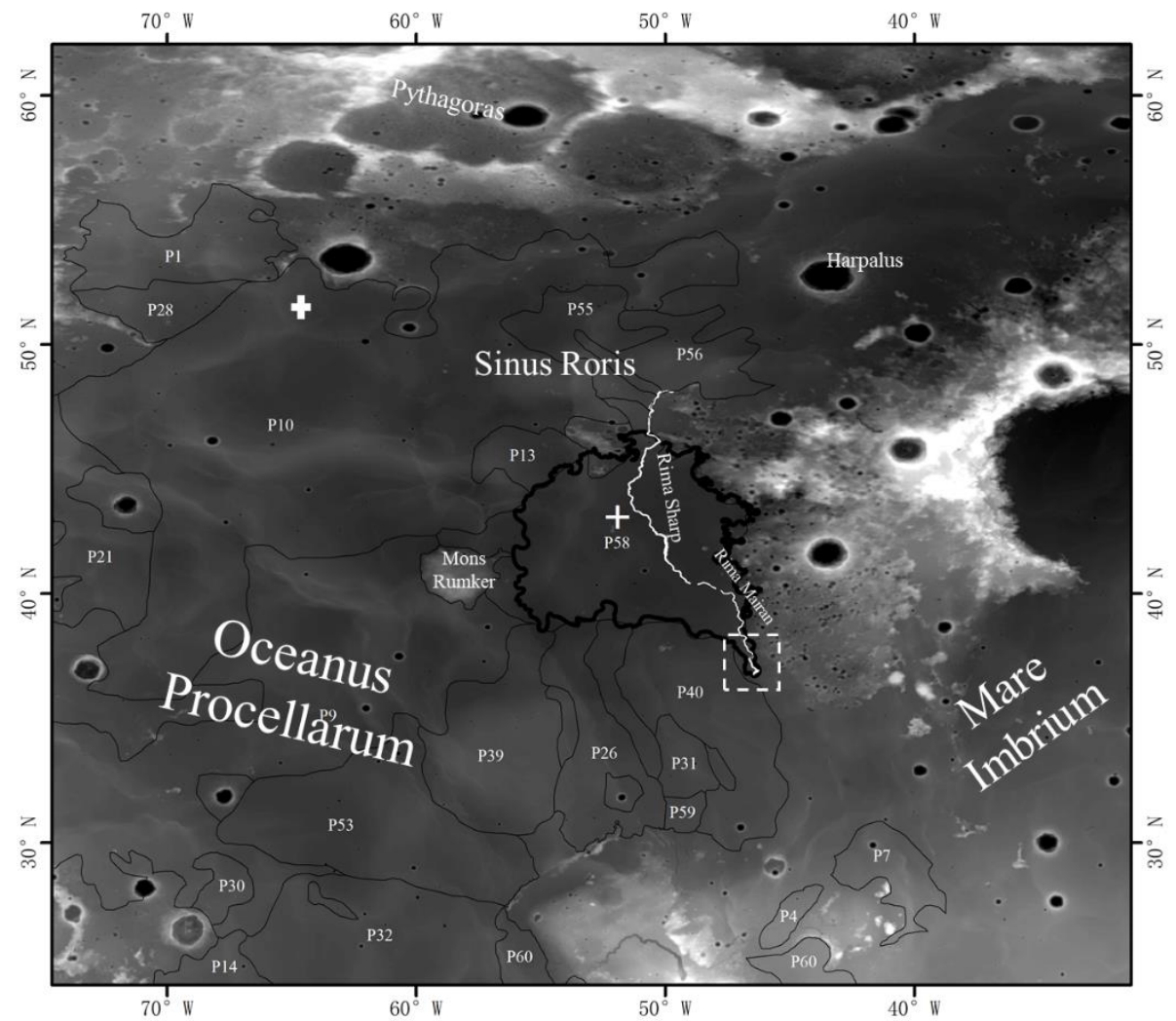

Figure 1. The location of the Chang'e-5 landing area and the spatial extent of this study (dashed box). The base map is Chang'e-2 (CE-2) DEM data.

Dark mantle deposits (DMD), also known as lunar pyroclastic deposits (LPD), generally present a dark and smooth surface and are often accompanied by lunar valleys, asymmetric depressions, or candidate volcanic vents of explosive volcanic origin (e.g., [13,14]) DMDs can be divided into two types according to their sizes: regional DMD and local DMD. Reginal DMDs are larger and are formed in long-duration Hawaiian-style eruptions, while smaller local DMDs result from Vulcanian/Strombolian explosive eruptions $[13,14]$. DMD material comes from the rapid ascent of the gas-rich primitive magma or late-stage cumulates. Analyses of lunar samples and remote sensing data both reveal that DMDs are composed of mafic materials, while they are more volatile-enriched and less fractionated compared to mare basalts. Volcanic glasses, which are often accompanied by DMDs, come from primary magma or late-stage magma remnants, which make them a probe for researching the interior of the Moon. Volcanic glasses are therefore of great significance when attempting to reveal the origin and evolution of basaltic magmatism on the Moon. Laboratory sample analysis and remote sensing data interpretation have shown 
that DMDs are mainly composed of iron- and titanium-enriched mafic components coated with volatile-rich materials, including $\mathrm{Fe}^{2+}$-bearing glass, iron- and titanium-rich glass, and devitrified beads with a similar composition [14-19]. The samples collected by CE-5 contain some glasses [20], but it is not yet clear whether they are from impact or volcanic origin. Therefore, it is necessary to conduct research on the related volcanic background.

Isolated elongated, circular, and irregular volcanic depressions/pits usually lack highraised crater rims and obvious ejecta, which make them different from impact craters. They usually exist on the top of the volcanic domes or near the mare volcanic source areas [21]. Their formation mechanism varies and is supposed to be related to late magma retreat, the collapse caused by gas release at the top of dikes, the collapse of lava tubes, or small explosive eruptions [21]. Irregular mare patches (IMPs) are special geological features on the lunar surface that are known for their uniquely shaped mounds and depressions. The most representative IMP is Ina [22], which is located in Lacus Felicitatis and was first discovered on Apollo 15 orbital photography. Early on, Ina was believed to have resulted from the collapse on the top of a volcanic dome $[23,24]$. In addition to the very typical morphology of protrusions and depressions, newly acquired high-resolution LROC NAC images provided chances to recognize that another IMP type that is characterized only by its irregular depressions and that has an extremely "young" appearance. Scholars have proposed a variety of explanations for what causes them, including degassing in the past 10 million years [25], lava flow expansion [26], young (within 100 million years) volcanic events [27], dark mantle deposits [28], and magmatic foam extrusions underlying lava lakes [29-31].

Based on the volcanic morphologic and compositional features described above, this study was conducted to investigate the volcanic morphology related to the gas eruption in the CE-5 landing zone. We found that in addition to the volcanic vents and sinuous rilles at the southern end of the Rima Mairan [5], there are also some unusual explosive volcanic features. The appearance of gas-related volcanic morphologies implies a volatileinvolved magmatic history and may help deepen our understanding of late-stage lunar thermal evolution.

\section{Materials and Methods}

The Chang'e-2 (CE-2) CCD stereo camera acquired digital orthophoto data (DOM) and a digital elevation model (DEM) of the whole Moon. The DOM data used in this study were acquired at an orbital height of $100 \mathrm{~km}$ with a spatial resolution greater than $7 \mathrm{~m} /$ pixel and an imaging spectral range of $0.45 \sim 0.52 \mu \mathrm{m}$ [32]. Most of the CE-2 DOM images were taken with an incidence angle greater than $30^{\circ}$, making the images less affected by terrain shading effects than images obtained with low sun illuminations and more able to comprehensively display lunar material information [33]. Because the albedo of DMDs is usually lower than the surrounding materials, the CE-2 DOM data were mainly used to recognize and distinguish DMD regions in this study. The CE-2 DEM with a spatial resolution of $7 \mathrm{~m} /$ pixel were used to highlight subtle topography variations within small volcanic features. We also employed CE-2 DOM images and matching DEM data to construct the local 3D image of the DMDs to illustrate the surrounding topography.

The multiband imager (MI) is a high-resolution multiband imaging camera with a spatial resolution in visible bands of $20 \mathrm{~m} /$ pixel and a spatial resolution in near-infrared bands of $62 \mathrm{~m} /$ pixel from the $100 \mathrm{~km}$ SELENE (KAGUYA) orbit altitude [34]. The MIderived titanium distribution map created using empirical Equations (1)-(2) from [35] and the iron distribution map created using an updated method (Equations (3)-(5)) from [36] were employed to confine and investigate the compositions of the DMD areas in this study. The calculation equations for $\mathrm{TiO}_{2}$ and $\mathrm{FeO}$ are as follows:

$$
\begin{gathered}
\theta_{T i}=\arctan \left(\frac{R_{415} / R_{750}-0.208}{R_{750}-(-0.108)}\right) \\
\mathrm{wt} \% \mathrm{TiO}_{2}=0.72 \times \theta_{T i}^{14.964}
\end{gathered}
$$




$$
\begin{gathered}
\theta_{F e 1}=-\arctan \left(\frac{R_{950} / R_{750}-1.39}{R_{750}-0.04}\right) \\
\theta_{F e 2}=0.0656^{3.6681 \times \theta_{F e 1}} \\
\mathrm{wt} \% \mathrm{FeO}=\left(1.0708 \times \theta_{F e 2}\right)-0.3986
\end{gathered}
$$

Moon Mineralogy Mapper $\left(\mathrm{M}^{3}\right)$ data cover a spectral range from 0.4 to $3 \mu \mathrm{m}$, with a spectral resolution of 20 and $40 \mathrm{~nm}$ [37]. The $\mathrm{M}^{3}$ data used in this study are M3G20090209T0 54031_V01_L2, which were acquired in the optical period OP1B with an average spatial resolution of $140 \mathrm{~m} /$ pixel. $\mathrm{M}^{3}$ data were used to analyze the DMD composition and to recognize potential volcanic glass signals. Integrated band depths (IBD) of $\mathrm{M}^{3}$ data, which aim to highlight the spectra shape and absorption center, are often used to display mineralogical differences across the lunar surface. IBD is sensitive to the composition and abundance of minerals. The absorption peaks of lunar mafic minerals are mainly located at around $1 \mu \mathrm{m}$ and $2 \mu \mathrm{m}$. Pyroxenes display strong absorption features both at 1 and $2 \mu \mathrm{m}$ (e.g., [38-40]). While the olivine has a broad and asymmetric absorption at around $1 \mu \mathrm{m}$, it lacks the absorption at $2 \mu \mathrm{m}$ (e.g., [38]). Fe-rich glasses show a longer absorption center at $1 \mu \mathrm{m}$ and a shorter center at $2 \mu \mathrm{m}$ compared to pyroxenes (e.g., [41]). The commonly used false-color parameter map is a composite of an IBD around $1 \mu \mathrm{m}$ (with red), an IBD around $2 \mu \mathrm{m}$ (with green), and reflectance at $1580 \mathrm{~nm}$ (with blue). The color therefore depends on the relative strength of Band I and Band II, with a red hue indicating a stronger Band I absorption, a green hue indicating a relatively stronger Band II absorption, while blue indicates that both Band I and Band II have weak absorption. Traditionally, highlands with weak mafic absorptions are blue, whereas regions rich in mafic minerals are yellow/green to orange/red, depending on the relative ferrous band strengths resulting from differences in mineralogy and optical maturity [42]. In this study, we also used the $\mathrm{M}^{3}$ IBD parameter map to emphasize and distinguish the difference between DMDs and surrounding materials. The IBD calculation method is slightly different from the traditional method as a result of the special mineralogical composition of DMD. The calculation equation of IBD [43] at $1 \mu \mathrm{m}$ and $2 \mu \mathrm{m}$ were as follows:

$$
\begin{aligned}
\mathrm{IBD} 1000 & =\sum_{n=0}^{26}\left(\frac{R(789+20 n)}{R_{C}(789+20 n)}\right) \\
\mathrm{IBD} 2000 & =\sum_{n=0}^{42}\left(\frac{R(1658+20 n)}{R_{C}(1658+20 n)}\right)
\end{aligned}
$$

where $R$ is the reflectance at a given wavelength, and $R_{C}$ is the spectral continuum defined as the straight-line segments that connect the reflectance at 730,1620, and $2580 \mathrm{~nm}$. In addition to the calculated IBD parameter map, individual spectral bands were also extracted. We tried to circle the regions of interest (ROI) in the target areas and achieved averaged spectra; however, for the places where it is difficult to circle the ROI, we chose the most distinct pixel to extract the spectra. We removed the spectra that were longer than $2497 \mathrm{~nm}$ to exclude the thermal effect [44] and smoothed the spectrum by means of the 3-point moving average method to reduce the effect of noise. A fixed straight-line method was used to remove the continuum of each spectrum, 0.73 and $1.62 \mu \mathrm{m}$ were used for Band I, and 1.62 and $2.58 \mu \mathrm{m}$ were used at the Band II, which was also adopted from [43].

Spectra parameters, specifically the band centers of Band I and Band II, were calculated to distinguish the composition discrepancy between the targets. Fourth-order polynomials were employed to fit the continuum-removed spectra around the two absorption bands of Band I and Band II. The corresponding wavelengths of the minimum polynomials were then determined to be the two band centers.

LRO narrow-angle camera (NAC) data were used for detailed studies of small volcanic features due to their high spatial resolution (up to $\sim 0.5 \mathrm{~m} /$ pixel) and more variable illumination conditions [45]. The LROC NAC image was produced from raw EDR (experiment data record) data through routine process sequences using the USGS Integrated Software 
for Imagers and Spectrometers [46]. The data used in this study include M1119193339RE, M175576283RC, and M1136846619RC.

\section{Results}

Based on the morphological and compositional characteristics of the typical gasrelated volcanic landforms described previously, we found that there are some similar volcanic features near the source area of Rima Mairan within the geologic unit where CE-5 is located.

\subsection{The Morphology and Composition of DMDs}

Three abnormal patches are distributed along the southern end of Rima Mairan (Figure 2). They are obvious in the CE-2 DOM image $(0.45 \sim 0.52 \mu \mathrm{m})$ and the $\mathrm{M}^{3} 2.49 \mu \mathrm{m}$ band, which show that their overall albedo is significantly lower than the surrounding material. The MI-derived titanium and iron content map shows that the $\mathrm{TiO}_{2}$ and $\mathrm{FeO}$ contents in these three patches, which are $\sim 5-10.5 \mathrm{wt} \%$ and $\sim 18-20 \mathrm{wt} \%$, respectively, are higher than concentrations of the surrounding substances. The $\mathrm{M}^{3}$ IBD image shows a yellow-green color; This is different from the orange-red to purple Eratosthenian basalts, yellow Imbrian basalts, and the blue highland material, indicating a different mineral composition. The boundary of these features is relatively fuzzy, but based on multiple data, we have drawn rough boundaries. From north to south, we refer to these boundaries as NDMD, M-DMD, and S-DMD (Figure 2a). All three DMDs are located next to Rima Mairan. N-DMD is cut by Rima Mairan and is divided into two parts: NE-DMD and NW-DMD. Among the DMDs, NE-DMD is the largest and displays the most distinct characteristics in multiple remote sensing data.

Figure $3 a-d$ shows the morphological characteristics of N-DMD. The uplifts on the left and right sides (annotated by arrows in Figure 3c,d) are kipukas, which are $\sim 20 \mathrm{~m}$ and $\sim 40 \mathrm{~m}$ higher than the lunar surface, respectively. The kipukas on the right are mantled with dark substances. The kipuka located in the south of the N-DMD, with a diameter of $\sim 5 \mathrm{~km}$, has an interactive relationship with Rima Mairan, which is not only intersected by but also is partly covered by the rille, revealing the erosion of the kipukas basement by the rille and the tectonic collapse of the kipuka material. Rima Mairan flows from south to north and has a depth of $\sim 50 \mathrm{~m}$; lava accumulates on the west bank of the rille to form a levee with a height of $\sim 30 \mathrm{~m}$. There is almost no accumulation on the east bank, and the sinuous rille was directly eroded from the original lunar surface. The size of the NW-DMD is $\sim 2 \times 4 \mathrm{~km}$, and the size of the NE-DMD is $\sim 3 \times 6 \mathrm{~km}$. It is speculated that its original size before being split was $\sim 6 \times 6 \mathrm{~km}$, which should be classified to the local DMD.

The areal extent of the M-DMD and the S-DMD is relatively small. The size of the M-LPD is $\sim 1.5 \times 2 \mathrm{~km}$, and the size of the S-DMD is $\sim 1.6 \times 2.3 \mathrm{~km}$. They are both cut by the rille, and their western boundaries share borders with Rima Mairan. No obvious volcanic vents were recognized. The S-DMD is relatively close to the vents of Rima Mairan, and there are some irregular depressions located around its range, which we will describe in detail in Section 3.2. The DEM data show that the three DMDs display no obvious topographic relief variation compared to the surrounding lunar surface (Figure $3 b, \mathrm{~d}, \mathrm{f}, \mathrm{h}$ ), indicating that the thickness of the dark mantling layer is relatively thin. 

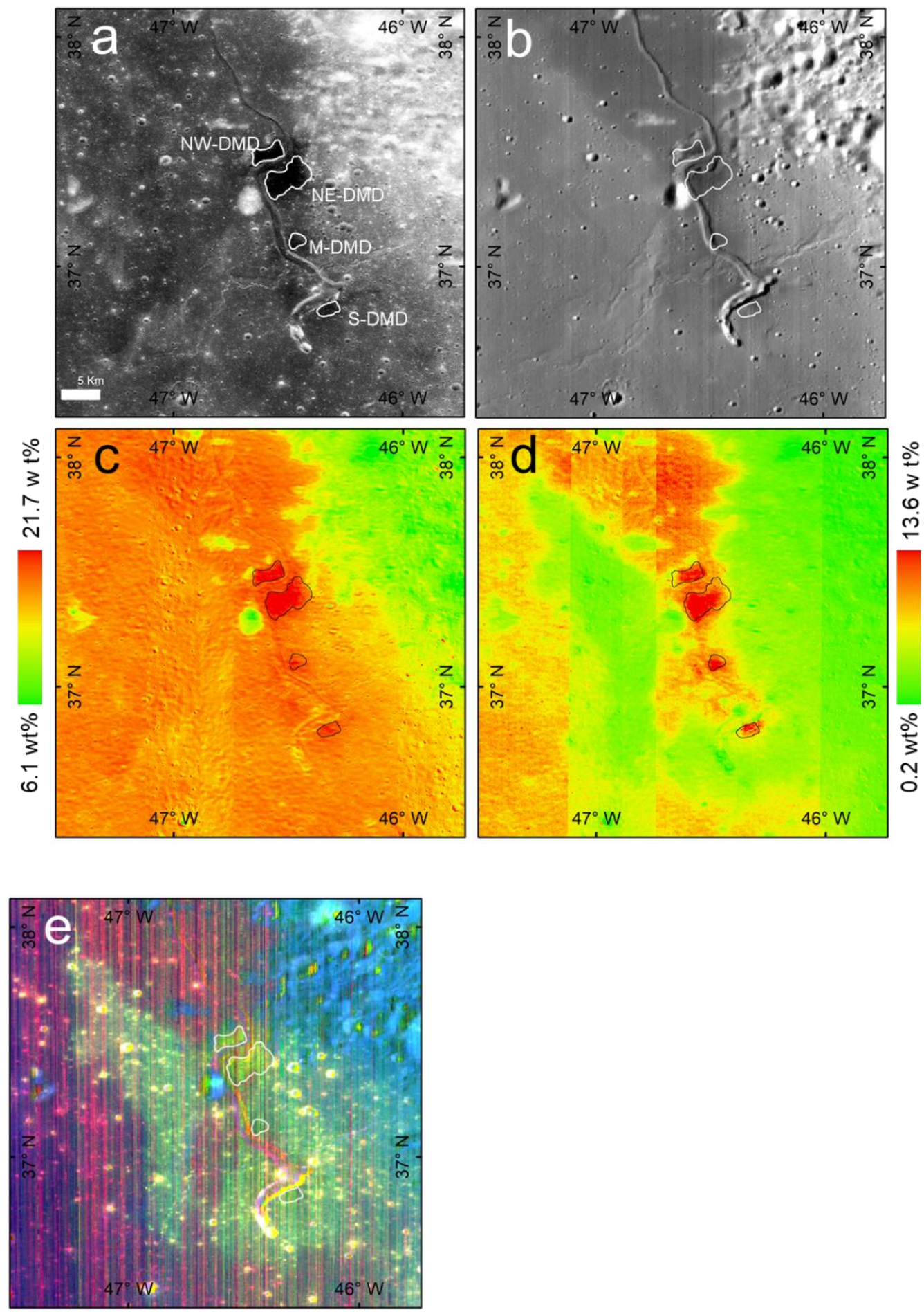

Figure 2. The geologic background of the researched area, with white circles denoting dark mantle deposits (DMDs). (a) CE-2 DOM data: DMDs are abnormally dark. (b) $\mathrm{M}^{3}$ Reflectance at $2.49 \mu \mathrm{m}$. (c) MI-derived $\mathrm{FeO}$ content distribution. (d) MI-derived $\mathrm{TiO}_{2}$ content distribution map. DMDs show higher iron and titanium contents. (e) $\mathrm{M}^{3}$ IBD false-color image. Red for $1 \mu \mathrm{m}$ IBD, green for $2 \mu \mathrm{m}$ IBD, and blue for reflectance at $1.58 \mu \mathrm{m}$. The regions rich in mafic minerals are yellow/green to orange/red, while the highlands are blue. The DMDs display a yellow-green, which is different from the surrounding materials. 

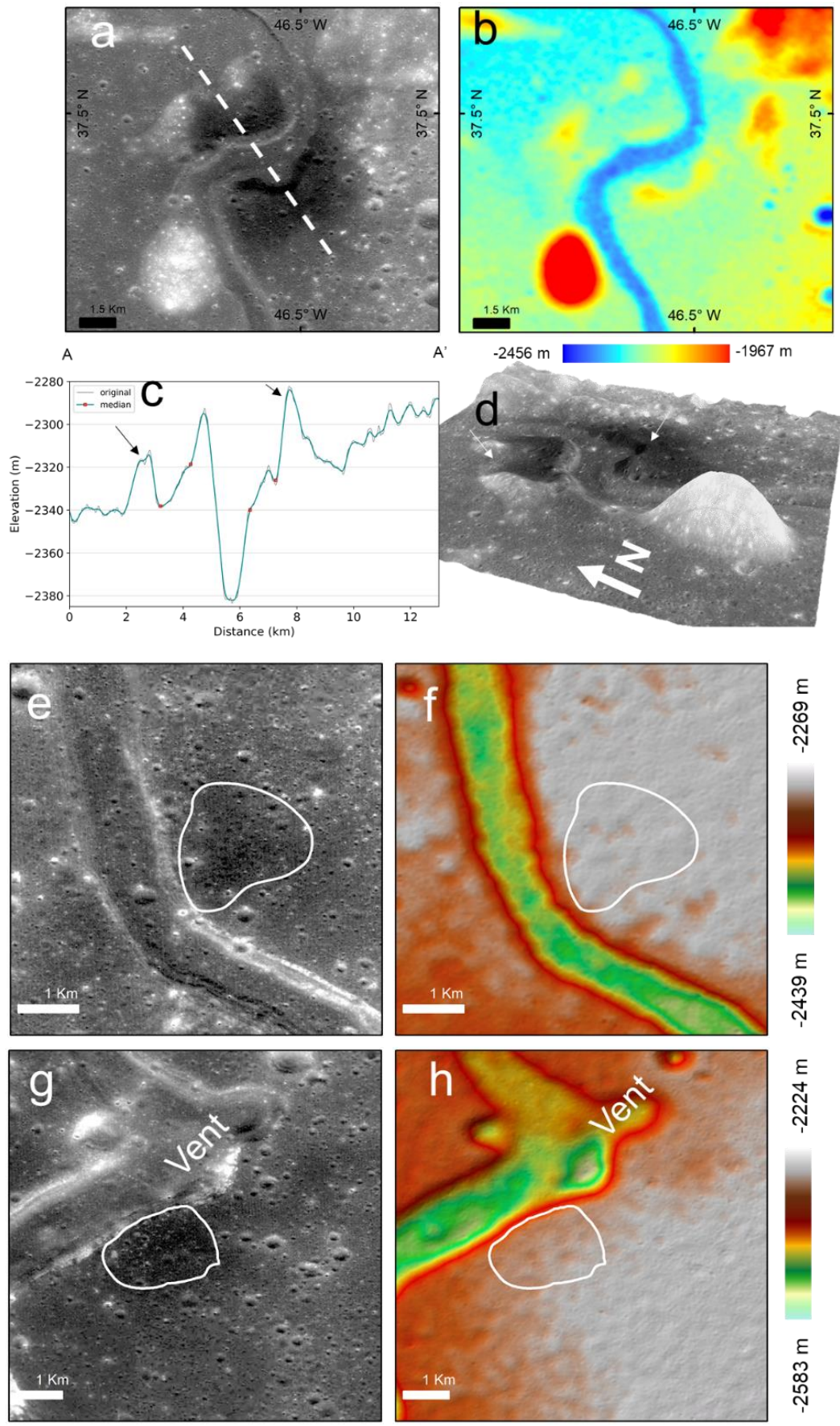

Figure 3. The morphological characteristics of three DMDs. (a,b) CE-2 DOM image and DEM data of N-DMD. (c) The profile extracted along the white dashed line in (a). The left-side two red points refer to the west bank of the rille, while the remnant refers to the east bank. Two uplifts on the two sides of the rille are annotated by arrows. (d) The three-dimensional topographic map of N-DMD based on $(\mathbf{a}, \mathbf{b})$. (e,f) The morphological characteristics of M-DMD shown in the CE-2 DOM image and the shaded relief DEM data. ( $g, h)$ The morphological characteristics of S-DMD shown in the CE-2 DOM image and the shaded relief DEM data.

Based on the $\mathrm{M}^{3}$ data and the IBD images, the averaged spectra were extracted from different ROIs, including Imbrian basalts (Im in purple), Eratosthenian basalts (P40 in cyan and P58 in pink), highland/kipukas (in blue), and DMDs (in red) (Figure 4). Among them, the smaller M-DMD and S-DMD may have been greatly affected by mixing from adjacent materials, so only an individual pixel (red crosses) was selected to extract the 
spectrum. Both the highland and mare materials exhibit the absorption characteristics of mafic minerals. Among them, the highland materials have the highest absolute reflectance; their $1 \mu \mathrm{m}$ band centers (BC1s) are located at $\sim 930 \mathrm{~nm}$, and their $2 \mu \mathrm{m}$ band centers (BC2s) are located $\sim 2000 \mathrm{~nm}$, suggesting the existence of low-calcium pyroxene. The BC1s of Imbrian basalt $(\mathrm{Im})$ are around $1000 \mathrm{~nm}$ and the BC2s are shorter than $2200 \mathrm{~nm}$. The BC1s of the Eratosthenian basalts (P40 and P58) appear longer than $1000 \mathrm{~nm}$, and their spectra show a slightly weaker $2 \mu \mathrm{m}$ absorption, with the absorption centers at 2250-2300 nm, indicating a higher abundance of high-calcium pyroxene than the Im basalts. In comparison, the DMDs show the lowest absolute reflectance. Their spectra have wider and more asymmetrical $1 \mu \mathrm{m}$ absorption than the nearby basalts, especially in terms of the continuum-removed spectra. Moreover, the $\mathrm{BC} 1 \mathrm{~s}$ of the DMDs are around $1050 \mathrm{~nm}$, while the $\mathrm{BC} 2 \mathrm{~s}$ are relatively shorter than those of the Eratosthenian basalts.
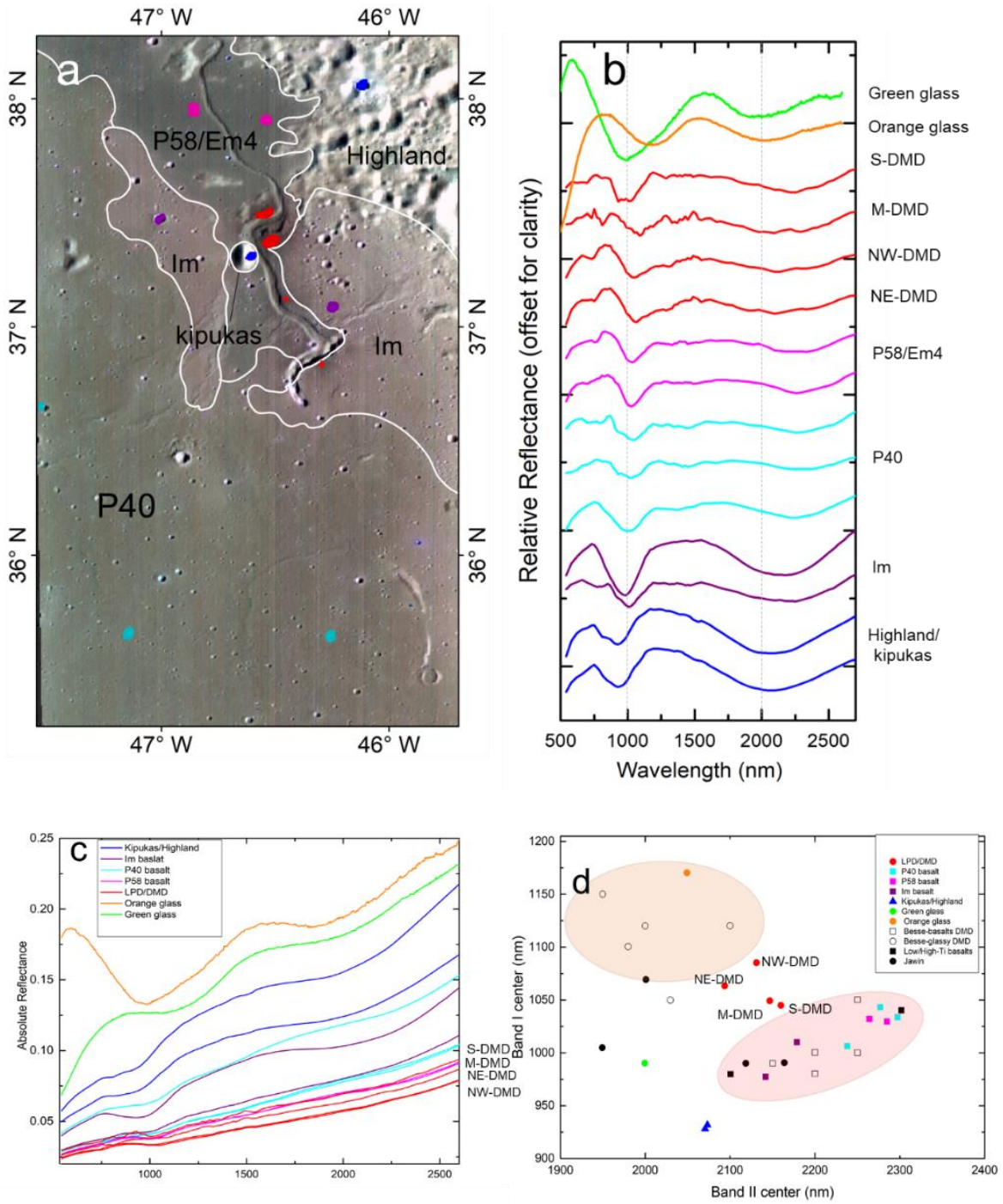

Figure 4. Spectra of DMDs and surrounding materials. (a) The location of the extracted spectra. $(\mathbf{c}, \mathbf{b})$ are the original spectra and the continuum-removed spectra, respectively. The laboratory spectra of orange (Apollo 17 sample 74220) and green volcanic glasses (Apollo 15 sample 15401) are also displayed [18,47]. (d) Band center positions at $1 \mu \mathrm{m}$ and $2 \mu \mathrm{m}$ extracted from the continuumremoved Figure $4 \mathrm{~b}$. The band positions of low- and high-Ti basalts were extracted from [42] and are marked using black squares. The band positions of the DMDs marked by black dots were extracted from $[16,43]$. The DMDs in this study is located halfway between two populations of orange glasses (orange area) and mare basalts (pink area). 


\subsection{Irregular Mare Depressions}

\subsubsection{A Depression near South Vents of Rima Mairan}

There is a nearly triangular irregular depression with a size of $\sim 0.8 \times 1.5 \mathrm{~km}$ located $\sim 20 \mathrm{~km}$ to the east of the Rima Sharp vent (Figure 5). The profile extracted from the CE-2 DEM data shows that there are no high-raised rims, and its depth is $\sim 20 \mathrm{~m}$. The absence of uplifted rims and ejecta eliminates impact origin as a possibility. As it is close to the vent, it is more likely to be a crater of volcanic origin.
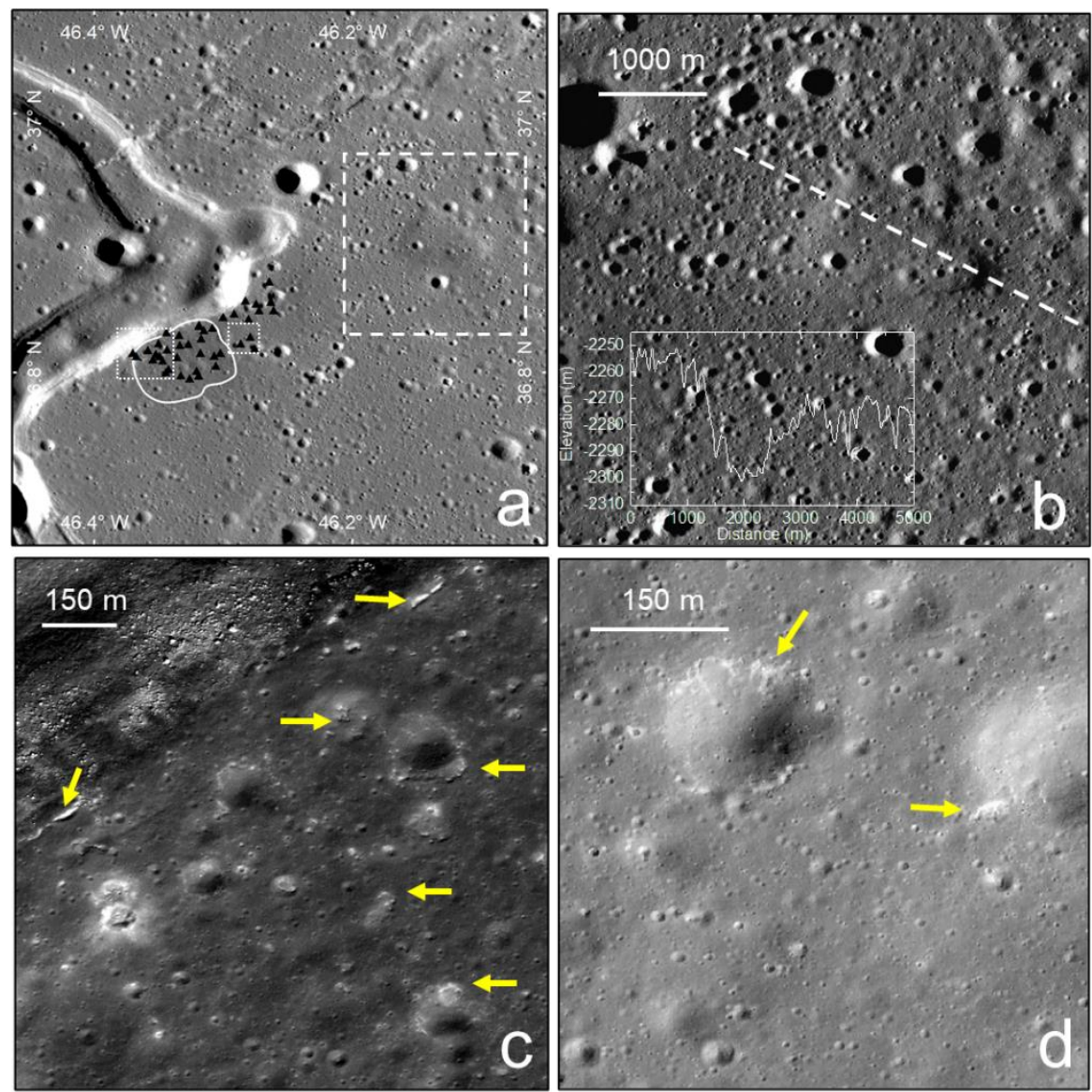

Figure 5. The gas-related volcanic features near the vent of Rima Mairan. (a) The full view of the location, with black triangle marking the irregular mare patches (IMPs), the white dashed box marking the location of (b), and the dotted box is (c) and (d) from left to right, respectively; (b) is an irregular volcanic depression/pit. (c,d) Some IMPs annotated by yellow arrows.

\subsubsection{Irregular Mare Patches}

Previously, four volcanic vents have been identified in the southern end of Rima Mairan, named SV1-SV4 from south to north [5]. We found that there are some unusually bright irregular mare patches (IMPs) there compared on to the surrounding lunar surface in this area, which makes them look "fresh" and young. The IMPs are tens of meters in size, and their maximum size is no more than $100 \mathrm{~m}$. The newly recognized IMPs in this study are located near SV3 and are distributed in clusters along the east bank of Rima Mairan (Figure 5a). Almost all of them are located at the edge of SV3 and extend southward to the S-DMD range; most of them are located at the edge of the rille or the rims of impact craters. 


\section{Discussion}

\subsection{Volcanic Glasses within DMD}

In this study, four spectra were extracted from three DMDs. Among them, the absolute reflectance of N-DMD and M-DMD was significantly lower than that of surrounding materials, which was consistent with the dark properties of the DMDs. While the reflectance of the smaller S-DMD is relatively high, this could be because it has been contaminated by surrounding materials. The DMD spectra present a wide and asymmetric shape of around $1 \mu \mathrm{m}$ with band centers longer than $1 \mu \mathrm{m}$ (Figure $4 \mathrm{~b}, \mathrm{c}$ ). Previously limited by the wavelength range of the spectral data, some believe that the asymmetrical spectral absorption feature seen at around $1 \mu \mathrm{m}$ is caused by olivine [48,49]. Recent studies based on spectra data covering the $2 \mu \mathrm{m}$ band suggest that this absorption feature is more likely to be due to the mixing of iron-containing volcanic glass and pyroxene $[43,50]$.

In order to further confirm the glass composition, we calculated and plotted the $1 \mu \mathrm{m}$ and $2 \mu \mathrm{m}$ absorption centers of the DMD spectra (Figure $4 \mathrm{~d}$ ). In addition to the spectra chosen in this study, we also displayed the DMDs studied in [16,43], in which the continuum removal method is the same. The spectra of the green and orange volcanic glass collected by Apollo 15 and Apollo 17 were also shown in Figure 4c,d [18,47]. Due to the slight difference in the composition between the green and orange glass, the spectra display a slight difference: the orange glass has a $1 \mu \mathrm{m}$ band minimum shifted to a longer wavelength relative to the green glass, both of which shifted to longer wavelengths relative to the pyroxenes, and the strength of the $1 \mu \mathrm{m}$ band is notably stronger relative to the $2 \mu \mathrm{m}$ band strength for the green glass [43]. The newly discovered DMDs in this study fall between the mare basalts and the orange glass, indicating that it may be a mixture of orange volcanic glass and mare basalts. As the N-DMD is the largest, the relative content of the glass components appears to be the highest, while the smaller M-DMD and S-DMD tend to be the more affected by the mixing of surrounding mare basalt materials. Apart from the spectral features, the titanium content derived from the MI data also provides a good constraint on the orange glasses within the DMDs. Previous studies on pristine lunar glasses have revealed the large discrepancy in the $\mathrm{TiO}_{2}$ content between green and orange glasses [51]. The DMDs newly discovered in this study are relatively rich in $\mathrm{TiO}_{2}(\sim 5-10.5 \mathrm{wt} \%)$ compared to surrounding mare basalts, supporting a possible bearing of high-Ti orange glass. The presence of volcanic glass indicates that the small DMD in this study was formed in explosive eruption conditions that were Vulcanian or Strombolianstyle eruptions rather than Hawaiian-style eruptions, which would have produced larger DMDs. The formation process seen here is that gas accumulated on the top of the dikes, and when the pressure in the top cavity was large enough to break through the lunar surface, volatile foam and liquid magma droplets were rapidly ejected outwards and were quickly quenched to form volcanic glass $[10,12,16,21]$.

\subsection{Gas-Related Volcanic Process}

The individual volcanic pit/depressions, IMPs, and multiple DMDs distributed near the source area of Rima Mairan are all gas-related volcanic features, indicating the source of gas-rich magma in this area. After experiencing the earlier gas release, the volcanic activity in this area turned from explosive to effusive eruptions and gradually formed extensive basalt and Rima Mairan. The intersection history of Rima Mairan indicates that the gas-rich magma eruption occurred before the rille formed, which was earlier than $1.39 \mathrm{Ga}$ [5]. Given that no obvious volcanic vent was observed, we speculate that the vent may have been eroded and damaged. Moreover, parts of these DMDs are covered on the Eratosthenian basalt, and the AMA of the closest mare basalts is $~ 1.5-2.4 \mathrm{Ga}$ [3]. Thus, the age limit of the DMDs may be $1.4-2.4 \mathrm{Ga}$, indicating that they were formed during the Eratosthenian period. Most localized DMDs are from the late Imbrian age ( 3.2-3.7 Ga) [52-54], which corresponds to the peak of the volcanic lunar period [55]. However, the DMDs in this study were possibly formed in the Eratosthenian period, which is similar to the one special DMD near the Taruntius crater [56]. Previously, laboratory analyses revealed the volatile elements 
trapped in volcanic glasses at several sampling locations. Later, an investigation based on remote sensing data also confirmed the widespread distribution of indigenous water in the low-latitude regions of the Moon [9]. As the newly discovered DMDs are similar in appearance and composition to many typical lunar DMDs, we speculate that there may also be some volatile elements within the DMDs studied in this paper. Though the DMDs are small, their existence indicates that late volcanism produced some explosive volcanic deposits in the Northeastern Oceanus Procellarum, which characterizes the presence of enough volatile elements in the magmatic eruptions.

Previous studies on IMPs suggest that they may have different formation mechanisms. This study found that some IMPs are located on S-DMD, while some IMPs are outside the area of S-DMD. This suggests that the formation of IMPs due to DMDs [28] may not be reasonable. From the spatial distribution, IMPs are close to the volcanic vents SV3 and SV4, and they are more likely to have formed as a result of very vesicular lava eruptions emplacing them under the cooling surfaces of the lava lakes near the vents during the very last stage of local volcanism [29-31]. This phenomenon indicates that there might have been a lot of gas-rich volcanic events in the Rima Marian source area during the waning stage.

Qian et al. [5] suggest that the materials near the CE-5 landing site were mainly transported from Rima Sharp, while the possibility that Rima Mairan has contributed to the material near the landing site how not been absolutely ruled out. The DMDs and IMPs are all located near the source area of Rima Mairan, and a small amount of related material may have been transported along Rima Mairan to the vicinity of the CE-5 landing site. This supposition will require the identification and composition analyses of the volcanic glass in the CE-5 samples. Further analysis of volcanic glass will provide the most direct evidence for the composition of the magma reservoir.

\subsection{The Volcanic History in the Source Area}

Near the Rima Mairan source area, there are both explosive and effusive volcanic activities. Combined with recent research on the volcanic morphologies of the area (including Rima Mairan and its associated vents), we drew a detailed geological map of the area (Figure 6). Following the classification of different stages of lunar volcanic activity $[10,12,21]$, we summarized the history of the volcanic activity in this area as follows:

(1) At the very beginning of the volcanic period in the south region of Rima Mairan, the dike had only just reached the shallow lunar crust. Volatile elements gathered at the top of the dike, and the top gas released over time and formed a volcanic pit/depression;

(2) Some dikes quickly penetrated the lunar surface, with gases enriching their tops, creating transient explosive Vulcanian/Strombolian-style volcanic eruptions, forming thinlayered scattered dark mantle deposits;

(3) The volcanic activity gradually increased, and the dike base continued rising toward the lunar surface, resulting in high-flux Hawaiian-style eruptions. Many volatilepoor, low-viscosity, and high-flux lava flows continued to erupt, which first filled the nearby lowlands, and then flowed northward along the terrain. The long-duration erosion created Rima Mairan. During the continuous extension of Rima Mairan to the north, erosion destroyed the vents associated with the DMDs and split the N-DMD into two halves;

(4) In the waning stage, the magma flux gradually decreased to a low level, and the gases gathered at the top of the dikes and dissolved to form magma foam. The extruded vesicular magma accumulated under a cooling crust around the vent, and subsequent external forces, such the impact, events caused the collapse and formed of irregular mare patches. 


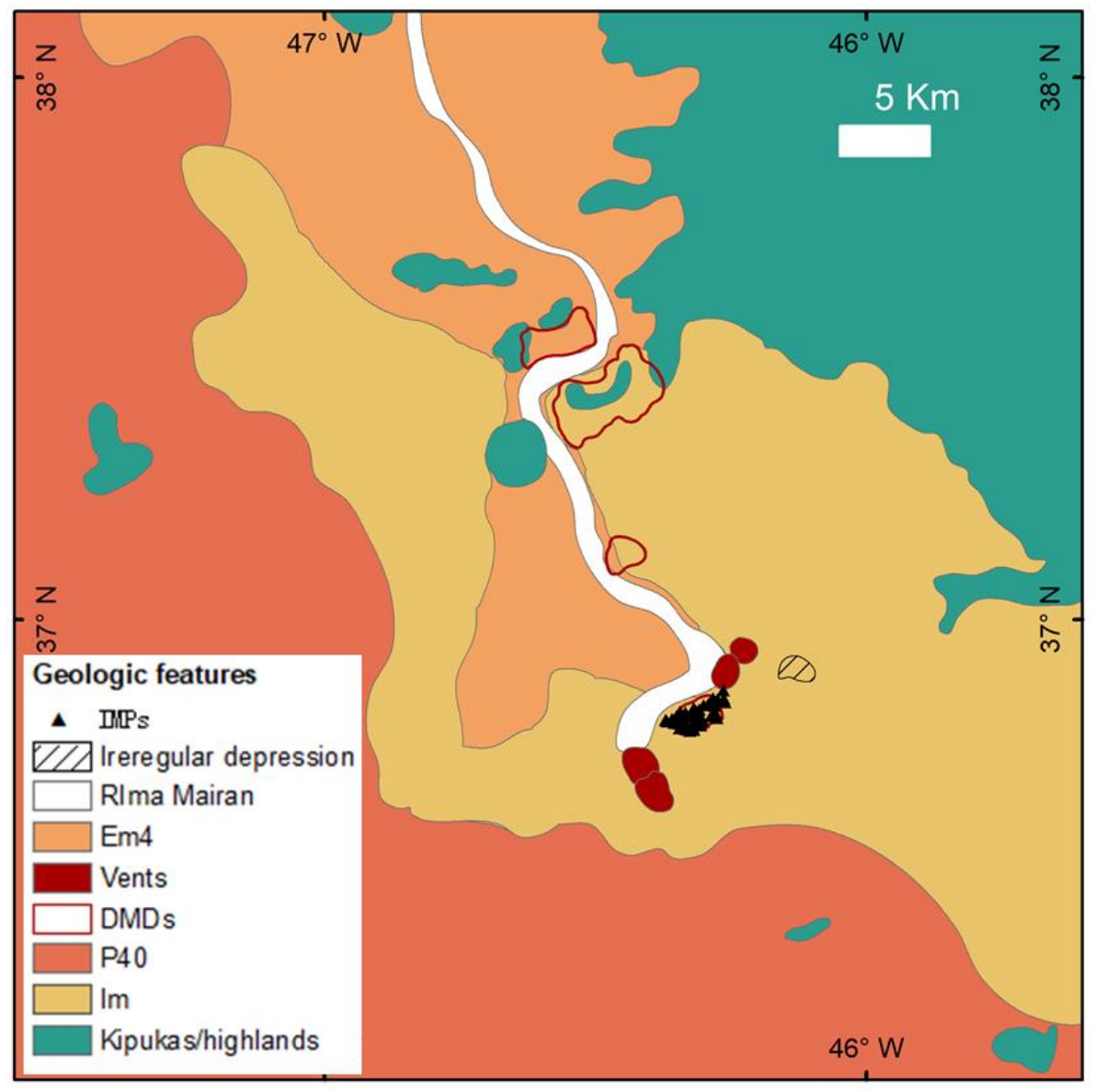

Figure 6. A sketch of the local geologic map.

\section{Conclusions}

The analysis based on CE-2 DOM and DEM data, LROC NAC images, the SELENE MIderived titanium and iron content distribution map, and $\mathrm{M}^{3}$ hyper-spectral data, suggests that dark mantle deposits, volcanic depressions, and irregular mare patches that are all related to gas eruptions exist at the southeastern end of the basaltic unit where the CE-5 landing area is located.

All of the DMDs were cut by the Rima Mairan, and they clearly formed before the rille. In addition, part of DMDs became mantled on the late-stage basalt. Therefore, we limit the age of the DMDs to 1.5-2.4 Ga, indicating that volcanic explosive eruptions occurred in the Eratosthenian period. The spectral analysis of the DMDs shows that their $1 \mu \mathrm{m}$ band absorption is wide and asymmetric, and the $1 \mu \mathrm{m}$ and $2 \mu \mathrm{m}$ absorption centers are closer to each other compared to the spectra of the basalts. Together with the relatively high $\mathrm{TiO}_{2}$ content within the DMDs, we infer that this refers to the signal of volcanic glass, especially orange glass.

Many IMPs are distributed along the east bank of Rima Mairan between its vent and S-DMD, implying the gas-rich magma extrusion in the waning stage of the volcanic activities within Oceanus Procellarum.

We drew a geological map of this area and summarized the volcanic activity process. There were both explosive and effusive volcanic activities in this area.

Author Contributions: Conceptualization, C.L. and Y.C.; writing-original draft preparation, Y.C.; writing-review and editing, X.W. and J.L. supervision, C.L. and X.R.; data curation, H.H.; funding acquisition, H.Z. All authors have read and agreed to the published version of the manuscript.

Funding: This study was funded by the National Natural Science Foundation (11941002) and the Key Research program of Chinese Academy of Sciences (ZDBS-SSW-JSC007-6). 
Data Availability Statement: The CE-2 data are archived in Lunar and Planetary Data Release System (https:/ / moon.bao.ac.cn/, accessed on 18 August 2021). The $\mathrm{M}^{3}$ and LROC data used in this paper are archived in NASA's Planetary Data System (www.pds.nasa.gov, accessed on 18 August 2021). The MI data were downloaded from "KADIAS" (https:/ / kadias.selene.darts.isas.jaxa.jp/index_e.html, accessed on 18 August 2021). All of the Data used in this study are available from the authors upon request.

Acknowledgments: We gratefully thank the science and engineer team members involved in all the datasets used in this study, particularly the Ground Research and Application System, who have contributed to data receiving and release of China's Chang'e-2 Lunar exploration Mission.

Conflicts of Interest: The authors declare no conflict of interest.

\section{References}

1. Hiesinger, H.; Head, J.; Wolf, U.; Jaumann, R.; Neukum, G. Ages and stratigraphy of mare basalts in oceanus procellarum, mare nubium, mare cognitum, and mare insularum. JGR Planets 2003, 108. [CrossRef]

2. Qian, Y.; Xiao, L.; Zhao, S.; Zhao, J.; Huang, J.; Flahaut, J.; Martinot, M.; Head, J.; Hiesinger, H.; Wang, G. Geology and scientific significance of the Rümker region in Northern Oceanus Procellarum: China's Chang'E-5 landing region. JGR Planets 2018, 123, 1407-1430. [CrossRef]

3. Qian, Y.; Xiao, L.; Head, J.W.; van der Bogert, C.H.; Hiesinger, H.; Wilson, L. Young lunar mare basalts in the Chang'e-5 sample return region, northern Oceanus Procellarum. Earth Planet. Sci. Lett. 2020, 555, 116702. [CrossRef]

4. Wu, B.; Huang, J.; Li, Y.; Wang, Y.; Peng, J. Rock Abundance and Crater Density in the Candidate Chang'E-5 Landing Region on the Moon. JGR Planets 2018, 123, 3256-3272. [CrossRef]

5. Qian, Y.; Xiao, L.; Head, J.W.; Wilson, L. The Long Sinuous Rille System in Northern Oceanus Procellarum and Its Relation to the Chang'e-5 Returned Samples. GRL 2021, 48, e2021GL092663. [CrossRef]

6. Qiao, L.; Chen, J.; Xu, L.; Wan, S.; Cao, H.; Li, B.; Ling, Z. Geology of the Chang'e-5 landing site: Constraints on the sources of samples returned from a young nearside mare. Icarus 2021, 364, 114480. [CrossRef]

7. Saal, A.E.; Hauri, E.H.; Cascio, M.L.; Van Orman, J.A.; Rutherford, M.C.; Cooper, R.F. Volatile content of lunar volcanic glasses and the presence of water in the Moon's interior. Nature 2008, 454, 192-195. [CrossRef]

8. Saal, A.E.; Hauri, E.H.; Van Orman, J.A.; Rutherford, M.J. Hydrogen isotopes in lunar volcanic glasses and melt inclusions reveal a carbonaceous chondrite heritage. Science 2013, 340, 1317-1320. [CrossRef]

9. Milliken, R.E.; Li, S. Remote detection of widespread indigenous water in lunar pyroclastic deposits. Nat. Geosci. 2017, 10, 561-565. [CrossRef]

10. Wilson, L.; Head, J.W. Generation, ascent and eruption of magma on the Moon: New insights into source depths, magma supply, intrusions and effusive/explosive eruptions (Part 1: Theory). Icarus 2017, 283, 146-175. [CrossRef]

11. Morgan, C.; Wilson, L.; Head, J.W. Formation and dispersal of pyroclasts on the Moon: Indicators of lunar magma volatile contents. J. Volcanol. Geotherm. Res. 2021, 413, 107217. [CrossRef]

12. Wilson, L.; Head, J.W. Controls on Lunar Basaltic Volcanic Eruption Structure and Morphology: Gas Release Patterns in Sequential Eruption Phases. GRL 2018, 45, 5852-5859. [CrossRef]

13. Wilson, L.; Head, J.W., III. Ascent and eruption of basaltic magma on the Earth and Moon. J. Geophys. Res. Solid Earth 1981, 86, 2971-3001. [CrossRef]

14. Gaddis, L.R.; Pieters, C.M.; Hawke, B.R. Remote sensing of lunar pyroclastic mantling deposits. Icarus 1985, 61, 461-489. [CrossRef]

15. Weitz, C.M.; Head, J.W. Spectral properties of the Marius Hills volcanic complex and implications for the formation of lunar domes and cones. JGR Planets 1999, 104, 18933-18956. [CrossRef]

16. Jawin, E.R.; Besse, S.; Gaddis, L.R.; Sunshine, J.M.; Head, J.W.; Mazrouei, S.J.J.o.G.R.P. Examining spectral variations in localized lunar dark mantle deposits. J. Geophys. Res. Planets 2015, 120, 1310-1331. [CrossRef]

17. Pieters, C.; McCord, T.B.; Zisk, S.; Adams, J.B. Lunar black spots and nature of the Apollo 17 landing area. J. Geophys. Res. 1973, 78, 5867-5875. [CrossRef]

18. Adams, J.; Pieters, C.; McCord, T. Orange glass-Evidence for regional deposits of pyroclastic origin on the moon. In Proceedings of the Lunar and Planetary Science Conference Proceedings, The Woodlands, TX, USA, 18-22 March 1974; pp. 171-186.

19. Lucey, P.G.; Hawke, B.R.; Pieters, C.; Head, J.; McCord, T. A compositional study of the Aristarchus region of the Moon using near-infrared reflectance spectroscopy. J. Geophys. Res. Solid Earth 1986, 91, 344-354. [CrossRef]

20. Li, C.; Hu, H.; Yang, M.F.; Pei, Z.Y.; Zhou, Q.; Ren, X.; Liu, B.; Liu, D.; Zeng, X.; Zhang, G.; et al. Characteristics of the lunar samples returned by Chang'E-5 Mission. Natl. Sci. Rev. under review. 2021.

21. Head, J.W.; Wilson, L. Generation, ascent and eruption of magma on the Moon: New insights into source depths, magma supply, intrusions and effusive/explosive eruptions (Part 2: Predicted emplacement processes and observations). Icarus 2017, 283, 176-223. [CrossRef]

22. Whitaker, E.A. An unusual mare feature. Apollo 15 Prelim. Sci. Rep. 1972, 289, 84. 
23. El-Baz, F. New geological findings in Apollo 15 lunar orbital photography. In Proceedings of the Lunar and Planetary Science Conference Proceedings, The Woodlands, TX, USA, 10-13 January 1972; p. 39.

24. Strain, P.L.; El Baz, F. The Geology and Morphology of Ina. In Proceedings of the Lunar and Planetary Science Conference Proceedings, The Woodlands, TX, USA, 7-12 March 1980; pp. 2437-2446.

25. Schultz, P.H.; Staid, M.I.; Pieters, C.M. Lunar activity from recent gas release. Nature 2006, 444, 184-186. [CrossRef]

26. Garry, W.B.; Robinson, M.S.; Zimbelman, J.R.; Bleacher, J.E.; Hawke, B.R.; Crumpler, L.S.; Braden, S.E.; Sato, H. The origin of Ina: Evidence for inflated lava flows on the Moon. J. Geophys. Res. Atmos. 2012, 117, 126-135. [CrossRef]

27. Braden, S.; Stopar, J.; Robinson, M.; Lawrence, S.; Van Der Bogert, C.; Hiesinger, H. Evidence for basaltic volcanism on the Moon within the past 100 million years. Nat. Geosci. 2014, 7, 787-791. [CrossRef]

28. Carter, L.; Hawke, B.; Garry, W.; Campbell, B.; Giguere, T.; Bussey, D. Radar observations of lunar hollow terrain. In Proceedings of the Lunar and Planetary Science Conference, The Woodlands, TX, USA, 18-22 March 2013; p. 2146.

29. Qiao, L.; Head, J.; Wilson, L.; Xiao, L.; Kreslavsky, M.; Dufek, J. Ina pit crater on the Moon: Extrusion of waning-stage lava lake magmatic foam results in extremely young crater retention ages. Geology 2017, 45, 455-458. [CrossRef]

30. Qiao, L.; Head, J.W.; Xiao, L.; Wilson, L.; Dufek, J.D. The role of substrate characteristics in producing anomalously young crater retention ages in volcanic deposits on the Moon: Morphology, topography, subresolution roughness, and mode of emplacement of the Sosigenes lunar irregular mare patch. Meteorit. Planet. Sci. 2018, 53, 778-812. [CrossRef]

31. Qiao, L.; Head, J.W.; Ling, Z.; Wilson, L. Lunar irregular mare patches: Classification, characteristics, geologic settings, updated catalog, origin, and outstanding questions. JGR Planets 2020, 125, e2019JE006362. [CrossRef]

32. Li, C.; Liu, J.; Ren, X.; Yan, W.; Zuo, W.; Mu, L.; Zhang, H.; Su, Y.; Wen, W.; Tan, X. Lunar Global High-precision Terrain Reconstruction Based on Chang'e-2 Stereo Images. Geomat. Inf. Sci. Wuhan Univ. 2018, 43, 485-495.

33. Zhao, B.; Li, C.; Huang, J.; Wen, D.; Yang, J.; Gao, W.; Ruan, P.; Xue, B.; Tang, Q. Analysis on In-orbit CCD Stereo Camera Images of Chang'e-2 Lunar Satellite. Spacecr. Eng. 2012, 21, 1-7.

34. Ohtake, M.; Haruyama, J.; Matsunaga, T.; Yokota, Y.; Morota, T.; Honda, C. Performance and scientific objectives of the SELENE (KAGUYA) Multiband Imager. Earth Planets Space 2008, 60, 257-264. [CrossRef]

35. Otake, H.; Ohtake, M.; Hirata, N. Lunar iron and titanium abundance algorithms based on SELENE (Kaguya) Multiband Imager data. In Proceedings of the Lunar and Planetary Science Conference, The Woodlands, TX, USA, 19-23 March 2012; p. 1905.

36. Lemelin, M.; Lucey, P.G.; Song, E.; Taylor, G.J. Lunar central peak mineralogy and iron content using the Kaguya Multiband Imager: Reassessment of the compositional structure of the lunar crust. J. Geophys. Res. Planets 2015, 120, 869-887. [CrossRef]

37. Pieters, C.M.; Boardman, J.; Buratti, B.; Chatterjee, A.; Clark, R.; Glavich, T.; Green, R.; Head, J., III; Isaacson, P.; Malaret, E. The Moon Mineralogy Mapper (M⿻3 $\left.{ }^{3}\right)$ on Chandrayaan-1. Curr. Sci. 2009, 96, 500-505.

38. Burns, R.G.; Burns, R.G. Mineralogical Applications of Crystal Field Theory; Cambridge University Press: Cambridge, UK, 1993.

39. Cloutis, E.A.; Gaffey, M.J. Pyroxene spectroscopy revisited: Spectral-Compositional correlations and relationship to geothermometry. JGR Planets 1991, 96, 22809-22826. [CrossRef]

40. Adams, J.B. Visible and near-Infrared diffuse reflectance spectra of pyroxenes as applied to remote sensing of solid objects in the solar system. J. Geophys. Res. 1974, 79, 4829-4836. [CrossRef]

41. Bell, P.; Mao, H.; Weeks, R. Optical spectra and electron paramagnetic resonance of lunar and synthetic glasses-A study of the effects of controlled atmosphere, composition, and temperature. In Proceedings of the Lunar and Planetary Science Conference Proceedings, The Woodlands, TX, USA, 15-19 March 1976; pp. 2543-2559.

42. Staid, M.I.; Pieters, C.M.; Besse, S.; Boardman, J.; Dhingra, D.; Green, R.; Head, J.; Isaacson, P.; Klima, R.; Kramer, G. The mineralogy of late stage lunar volcanism as observed by the Moon Mineralogy Mapper on Chandrayaan-1. JGR Planets 2011, 116. [CrossRef]

43. Besse, S.; Sunshine, J.; Gaddis, L.R. Volcanic glass signatures in spectroscopic survey of newly proposed lunar pyroclastic deposits. JGR Planets 2014, 119, 355-372. [CrossRef]

44. Clark, R.N.; Pieters, C.M.; Green, R.O.; Boardman, J.; Petro, N.E. Thermal removal from near-infrared imaging spectroscopy data of the Moon. JGR Planets 2011, 116. [CrossRef]

45. Robinson, M.; Brylow, S.; Tschimmel, M.; Humm, D.; Lawrence, S.; Thomas, P.; Denevi, B.; Bowman-Cisneros, E.; Zerr, J.; Ravine, M. Lunar reconnaissance orbiter camera (LROC) instrument overview. Space Sci. Rev. 2010, 150, 81-124. [CrossRef]

46. Anderson, J.; Sides, S.; Soltesz, D.; Sucharski, T.; Becker, K. Modernization of the integrated software for imagers and spectrometers. In Proceedings of the Lunar and Planetary Science Conference, The Woodlands, TX, USA, 15-19 March 2004; p. 2039.

47. Pieters, C.; Taylor, L.; McKay, D.; Wentworth, S.; Morris, R.; Keller, L. Spectral characterization of lunar mare soils. In Proceedings of the Lunar and Planetary Science Conference, The Woodlands, TX, USA, 13-17 March 2000; p. 1865.

48. Hawke, B.; Coombs, C.; Gaddis, L.; Lucey, P.; Owensby, P. Remote sensing and geologic studies of localized dark mantle deposits on the Moon. In Proceedings of the Lunar and Planetary Science Conference Proceedings, The Woodlands, TX, USA, 14-18 March 1988; pp. 255-268.

49. Hawke, B.; Coombs, C.; Clark, B. Ilmenite-rich pyroclastic deposits: An ideal lunar resource. In Lunar and Planetary Science Conference Proceedings; Lunar and Planetary Institute: Houston, TX, USA, 1990; pp. 249-258.

50. Horgan, B.H.; Cloutis, E.A.; Mann, P.; Bell, J.F., III. Near-infrared spectra of ferrous mineral mixtures and methods for their identification in planetary surface spectra. Icarus 2014, 234, 132-154. [CrossRef]

51. Delano, J.W. Pristine lunar glasses: Criteria, data, and implications. J. Geophys. Res. Solid Earth 1986, 91, 201-213. [CrossRef] 
52. Head, J. Lunar dark-mantle deposits-Possible clues to the distribution of early mare deposits. In Proceedings of the Lunar and Planetary Science Conference Proceedings, The Woodlands, TX, USA, 18-22 March 1974; pp. 207-222.

53. Gaddis, L.R.; Staid, M.I.; Tyburczy, J.A.; Hawke, B.R.; Petro, N.E. Compositional analyses of lunar pyroclastic deposits. Icarus 2003, 161, 262-280. [CrossRef]

54. Weitz, C.M. Lunar Pyroclastic Deposits and Effusive Constructs: Petrology, Eruption Styles, and Spectral Properties; Brown University: Providence, Rhode Island, 1998.

55. Hiesinger, H.; Jaumann, R.; Neukum, G.; Head, J.W. Ages of mare basalts on the lunar nearside. JGR Planets 2000, 105, 29239-29275. [CrossRef]

56. Spudis, P. Young dark mantle deposits on the Moon. In Proceedings of the NASA TM 4210; Lunar and Planetary Institute: Houston, TX, USA, 1990; pp. 406-407. 